\title{
Erectile Dysfunction Among Hypertensive Patients in Yaounde, Cameroon
}

\author{
Jerome Boombhi, ${ }^{1,2}$, Njoya Poumie Aoudou ${ }^{1}$, Alain Menanga ${ }^{1,2}$, Donald Tchapmi ${ }^{1}$, \\ Ba Hamadou ${ }^{1,2}$, Samuel Kingue ${ }^{1,2}$ \\ ${ }^{1}$ Department of Internal Medicine and Specialties, University of Yaounde I, Yaounde, Cameroon \\ ${ }^{2}$ Cardiology Unit, General Hospital of Yaounde, Yaounde, Cameroon
}

\section{Email address:}

boombhijerome@yahoo.fr (J. Boombhi), njoyapoumie@yahoo.fr (N. P. Aoudou), amenanga@yahoo.fr(A. Menanga), tn.donald@yahoo.fr(D. Tchapmi),drhamadouba@yahoo.fr(Ba Hamadou), samuel_kingue@yahoo.fr(S. Kingue)

${ }^{*}$ Corresponding author

\section{To cite this article:}

Jérôme Boombhi, Njoya Poumie Aoudou, Alain Menanga, Donald Tchapmi, Ba Hamadou, Samuel Kingue. Erectile Dysfunction Among Hypertensive Patients in Yaounde, Cameroon. Cardiology and Cardiovascular Research. Vol. 3, No. 4, 2019, pp. 90-93. doi: $10.11648 /$ j.ccr.20190304.13

Received: October 1, 2019; Accepted: October 28, 2019; Published: November 5, 2019

\begin{abstract}
This study was done to determine the prevalence, associated factors and severity factors of erectile dysfunction, in patients with hypertension in Yaounde. It was a cross sectional descriptive and analytical study that included 170 patients. All the participants were screened for erectile dysfunction using the International Index of Erectile Function 5 (IIEF-5). Results showed that the mean age of our participants was $55+/-8$ years. The prevalence of erectile dysfunction was $50.6 \%$. Among those affected, the severity was classified as mild (46,5\%), moderate $(33,7 \%)$ and severe $(19,8 \%)$. After a multivariate analysis, erectile dysfunction remained significantly associated with age $(\mathrm{p}<0,001)$, duration of hypertension of more than 5 years $(\mathrm{p}=0,001)$, higher grade of hypertension $(\mathrm{p}=0,011)$, diabetes $(\mathrm{aOR}=24,56 ; 95 \% \mathrm{CI}: 3,56-83,1 ; \mathrm{p}=0,02)$, tobacco smoking $(\mathrm{aOR}=4,83 ; 95 \% \mathrm{CI}: 2,70-33,2 ; \mathrm{p}=0,016)$, alcohol intake $(\mathrm{aOR}=43,1 ; 95 \% \mathrm{CI}: 2,53-732,7 ; \mathrm{p}=0,009)$, multiple antihypertensive medications ( $\mathrm{aOR}=3,7 ; 95 \% \mathrm{CI}: 1,51-6,78 ; \mathrm{p}=0,006)$ and usage of thiazide diuretics $(\mathrm{aOR}=14,3 ; 95 \% \mathrm{CI}: 4,32$ $-47,3 ; \mathrm{p}<0,001)$. The severity of erectile dysfunction was significantly associated with age ( $p<0,001)$, duration of hypertension $(p<0,001)$, severity of hypertension $(p<0,001)$, diabetes $(p<0,001)$, tobacco smoking $(p=0,003)$, alcohol intake $(p=0,003)$ and multiple antihypertensive medications $(p=0,001)$. In conclusion, erectile dysfunction has a high prevalence and severity among Cameroonian hypertensive patients. Age, duration of hypertension, severity of hypertension, diabetes, tobacco smoking, alcohol intake and usage of thiazide diuretics were factors associated with this high prevalence and severity.
\end{abstract}

Keywords: Erectile Dysfunction, Hypertension, Prevalence, Severity

\section{Introduction}

Erectile dysfunction (ED) is the inability (at least 6 months) to get or keep an erection firm enough for satisfactory sexual intercourse [1]. It is considered a public health issue as shown by the largest study done on it by Feldman in 1994, with a prevalence of 52\% [2]. In Africa, few studies have been done on erectile dysfunction because of the taboo nature of sexuality and the legendary myth of virility in black people. The prevalence of erectile dysfunction in hypertensive patients from a similar study done in Togo was 53\% [3].

Hypertension on the other hand is a global scourge. In 2000 , the world prevalence was $26,4 \%$ [4]. It is expected to rise to $29.2 \%$ by 2035 [4]. In Cameroon, the prevalence in the general population is $29.74 \%$ [5].

The relationship between hypertension and erectile dysfunction had been described long ago. The prevalence of ED is higher in patients with hypertension $(35.2 \%)$ than in those without (14.1\%) [6]. It is also higher among hypertensive patients receiving antihypertensive medications $(40.4 \%)$ than in those who don't take medications (19.8\%) 
[6].

In Cameroon, no specific study has been done to evaluate erectile function in people with hypertension. The goal of this study was to determine the prevalence, associated factors and severity factors of ED in patients with hypertension in Yaounde.

\section{Patients and Methods}

This was a cross sectional analytical study. Patients were recruited in the internal medicine unit of the Yaounde General Hospital and the cardiology unit of the Yaounde Central Hospital.

We included any hypertensive male patient aged 18 and above, taking anti-hypertensive medication and having accurate memories of his erectile function before the initiation of anti-hypertensive treatment.

We excluded any patient who had a non-vascular related disease that could impair erectile function: history of pelvic surgery, pelvic radiation therapy, obstructive urinary symptoms, psychiatric or neurologic diseases, medication known to disrupt erectile function except anti-hypertensive medications, marital conflicts. An informed consent was obtained from each patient.

Data obtained from history taking, physical examination and patient files were recorded using a pre-established questionnaire. Data collected were: age, duration of hypertension, severity of hypertension, current medications, body mass index, abdominal circumference, and other cardiovascular risk factors such as diabetes, tobacco smoking and dyslipidemia.

Evaluation of erectile function was done using the IIEF - 5 (International Index of Erectile Function 5) questionnaire [7]. An IIEF-5 score of 5 to 20 was diagnostic of erectile dysfunction. It was classified as severe, moderate or mild for scores ranging from 5 to 10,11 to 15 and 16 to 20 respectively.

Data analysis was done using Statistical package for social sciences version 20.0 (SPSS 20.0). Means were compared using the student $t$ test or the analysis of variance (ANOVA) test. Variables significantly associated to erectile dysfunction on bivariate analysis were then analysed using multivariate logistic regression. The degree of association was measured by the Odds ratio (OR).

\section{Results}

One hundred and seventy patients were included in the study. The mean age was 55+/- 8 years, ranging from 40 to 68 years. Most patients had a well-controlled blood pressure (BP) $(31.2 \%)$ or a grade 1 hypertension (30.6\%). $45.3 \%$ of the participants had hypertension for more than 10 years. Comorbidities found were diabetes $(26.5 \%)$, tobacco smoking $(8.2 \%)$, dyslipidemia $(24,7 \%)$, obesity $(27.6 \%)$, chronic alcohol intake (12.14\%). The patients were treated for hypertension by monotherapy in $45.2 \%$ of cases and by polytherapy in $54,8 \%$. (Table 1 )
Table 1. General characteristics of the study population.

\begin{tabular}{lll}
\hline Variables & Number & Percentage \\
\hline Age (years) & 52 & \\
$40-50$ & 60 & 30,58 \\
$50-60$ & 58 & 35,30 \\
$60-70$ & & 34,12 \\
Stage of hypertension & 53 & \\
Controlled blood pressure & 52 & 31,2 \\
Stage 1 & 46 & 30,6 \\
Stage 2 & 19 & 27,0 \\
Stage 3 & & 11,2 \\
Duration of hypertension (years) & 21 & \\
1-5 & 72 & 12,35 \\
5-10 & 77 & 42,35 \\
$\geq 10$ & & 45,30 \\
CVRF & 45 & \\
Diabetes & 14 & 26,5 \\
Tobacco smoking & 42 & 8,2 \\
Dyslipidemia & 41 & 24,7 \\
Obesity & & 27,6 \\
Anti-hypertensive therapy & 75 & 45,2 \\
Monotherapy & 91 & 54,8 \\
Polytherapy & & \\
Antihypertensive medication class & 85 & 50,0 \\
Thiazide diuretic & 4 & 10,6 \\
Anti-aldosterone & 90 & 7,6 \\
Calcium channel blocker & 13 & \\
ACE inhibitor & & \\
Angiotensin II receptor blocker & 58,9 \\
Beta blocker & 5 & \\
\hline & & \\
\hline
\end{tabular}

CVRF: Cardiovascular Risk Factor; ACE: Angiotensin Converting Enzyme

Erectile dysfunction was diagnosed in 86 patients (50.6\%). It was mild in $46,5 \%$, moderate in $33.7 \%$ and severe in $19.8 \%$ of the cases.

After multivariate analysis, age above 50 (adjusted $\mathrm{OR}=$ 4.8; 95\% CI: $[4.0-7.9] ; \mathrm{p}=0.001)$, high stage of hypertension $(\mathrm{aOR}=16.7 ; 95 \% \mathrm{CI}$ : $[2.77-100.4] ; \mathrm{p}=$ $0.001)$, diabetes $(\mathrm{aOR}=24.56 ; 95 \%$ CI: $[3.56-83.1]$; $\mathrm{p}=0.02)$, tobacco smoking $(\mathrm{aOR}=4.83 ; 95 \%$ CI $[2.70-$ 3.33 ; $\mathrm{p}=0.016)$, chronic alcohol intake $(\mathrm{aOR}=43.1 ; 95 \%$ CI:[2.53 - 732.7], $\mathrm{p}=0.009$ ), antihypertensive polytherapy $(\mathrm{aOR}=3.7 ; 95 \%$ CI: $[1.51-6.78] ; \mathrm{p}=0.006)$, thiazide diuretics $(\mathrm{aOR}=14.3,95 \%$ CI:[4.32 - 47.3]; $\mathrm{p}<0.001)$ were factors significantly associated with erectile dysfunction. No statistically significant association was found between erectile dysfunction and obesity, dyslipidemia, other classes of anti-hypertensive medications (calcium channel blockers, beta blockers, ACE inhibitors, angiotensin II receptor blockers). (Table 2)

Table 2. Multivariate analysis of factors associated with erectile dysfunction among hypertensive patients.

\begin{tabular}{lll}
\hline Variable & Adjusted OR (95\% CI) & p-value \\
\hline Age (years) & & \\
$40-50$ & 1 & $<0,001$ \\
$50-60$ & $4,8(4-7,9)$ & \\
$60-70$ & $5,2(4,3-9,2)$ & \\
Duration of hypertension & & 0,001 \\
$1-5$ & 1 & \\
$5-10$ & $10,1(3,67-92,7)$ & \\
$\geq 10$ & $13,2(2,11-106,4)$ & \\
Stage of hypertension & & \\
\hline
\end{tabular}




\begin{tabular}{lll}
\hline Variable & Adjusted OR (95\% CI) & p-value \\
\hline Controlled BP & 1 & 0,0011 \\
Stage 1 & $1,85(0,39-8,80)$ & \\
Stage 2 & $12,7(1,87-86,6)$ & \\
Stage 3 & $16,7(2,77-100,4)$ & \\
Tobacco smoking & $4,83(2,7-33,2)$ & 0,0016 \\
Dyslipidemia & $0,29(0,08-1,11)$ & 0,071 \\
Diabetes & $24,6(3,56-83,1)$ & 0,02 \\
Chronic alcohol intake & $43,1(2.53-732,7)$ & 0,02 \\
Obesity & $1,55(0,41-5,81)$ & 0,518 \\
Anti-hypertensive medications & & \\
Monotherapy & 1 & 0,006 \\
Polytherapy & $3,7(1,51-6,78)$ & \\
Calcium channel blockers & $1,20(0,41-47,3)$ & 0,744 \\
Thiazide diuretics & $14,3(4,34-47,3$ & $<0,001$ \\
Beta blockers & $3,53(0,55-22,6)$ & 0,18 \\
\hline
\end{tabular}

OR: Odds Ratio, CI: Confidence Interval, BP: Blood Pressure

The progressive decline in IIEF-5 score, implying an increase in severity of erectile dysfunction, was significantly associated with age $(\mathrm{p}<0.001)$, duration of hypertension ( $\mathrm{p}$ $<0.001)$, grade of hypertension $(\mathrm{p}<0.001)$ tobacco smoking $(p=0.003)$, diabetes $(p<0.001)$, utilisation of multiple antihypertensive medications $(\mathrm{p}=0.025)$ and chronic alcohol intake $(\mathrm{p}=0.003)$. Table 3 .

Table 3. Factors associated with the severity of erectile dysfunction.

\begin{tabular}{llc}
\hline Variable & IIEF-5 score (Mean \pm SD) & p-value \\
\hline Age (years) & & \\
$40-50$ & $16,38 \pm 3,99$ & $<0,001$ \\
$50-60$ & $16,24 \pm 2,86$ & \\
$60-70$ & $12,64 \pm 3,61$ & \\
Duration of hypertension & & $<0,001$ \\
$1-5$ & $16,36 \pm 3,02$ & \\
$5-10$ & $12,76 \pm 3,01$ & \\
$\geq 10$ & $9,22 \pm 3,49$ & $<0,001$ \\
Stage of hypertension & $16,31 \pm 3,21$ & \\
Controlled BP & $16,68 \pm 2,59$ & \\
Stage 1 & $12,96 \pm 2,1$ & \\
Stage 2 & $9,00 \pm 1,41$ & \\
Stage 3 & & \\
Diabetes & $12,38 \pm 3,43$ & \\
Yes & $15,56 \pm 3,19$ & \\
No & & \\
Dyslipidemia & $13,42 \pm 3,98$ & \\
Yes & $14,78 \pm 3,39$ & \\
No & & \\
Tobacco smoking & $11,36 \pm 4,23$ & \\
Yes & $14,81 \pm 3,22$ & 0,003 \\
No & & \\
Anti-hypertensive medications & $15,81 \pm 3,21$ & 0,003 \\
Monotherapy & $13,81 \pm 3,65$ & \\
Polytherapy & & \\
Chronic alcohol intake & $12,21 \pm 3,78$ & \\
Yes & $14,98 \pm 3,34$ & \\
No & & \\
\hline
\end{tabular}

IIEF-5: International Index of Erectile Function 5, BP: Blood Pressure, SD: Standard Deviation

\section{Discussion}

This study included 170 hypertensive patients. The prevalence of erectile dysfunction was $50.6 \%$. This value is similar to $56.2 \%$ and $53 \%$ obtained by studies done in Togo and Thailand $[3,8]$. In Nigeria, Fafiolu et al. had a prevalence of $65.8 \%$ which is higher than ours [9]. A study done among hypertensive patients in England by Aranda et al. found a prevalence of $35 \%$, which is lower than what we obtained [10]. These differences can be explained by the differences in methodology of the studies concerning the tools used to evaluate erectile function and exclusion criteria.

Age is a major risk factor of erectile dysfunction. Aging is accompanied by neurosensory deficits, lower testosterone levels, endothelial dysfunction and atherosclerosis, causing erectile dysfunction. In this study, the odds of having erectile dysfunction was 4.8 times higher for patients aged between 50 and 60 years, and 5.2 for those aged between 60 and 70 years. These results are similar to those of Fafiolu et al. in Nigeria, who found that the risk of erectile dysfunction was multiplied by 3 in hypertensive patients aged above 65 years [9].

Hypertension, its severity and duration, are known to be independent risk factors for erectile dysfunction due to atherosclerosis. Participants in this study had odds of erectile dysfunction multiplied by 1.85 for those with stage 2 hypertension and by 16.7 for those with stage 3 . The odds was multiplied by 13.2 for those who had hypertension for more than 10 years. These results are similar to those obtained by a study in Thailand, who had a fourfold increase in the prevalence erectile dysfunction in patients with hypertension for more than 5 years [8]. This finding can be explained by the progression of atherosclerosis and endothelial dysfunction with increasing duration and severity of hypertension [9].

Antihypertensive medications are known causes of erectile dysfunction. Thiazide diuretics impair the normal functioning of the smooth muscles of the cavernous bodies, causing a decrease response to catecholamines. Potassium sparing diuretics have an anti-androgenic effect. Some beta blocker through their anti-adrenergic effect are also causes of erectile dysfunction. Studies show that calcium channel blockers and blockers of the renin angiotensin aldosterone system have no effect on erectile function [11]. In this study, only thiazide diuretics were associated with erectile dysfunction $(\mathrm{OR}=$ $14.3, \mathrm{p}<001)$. The effect of anti-aldosterone medications on erectile function was not evaluated due to the low number of participants on these medications (4 patients). The THOMS study (Treatment in hypertensive men and women) had similar results, they found that only beta blockers, calcium channel blockers and thiazide diuretics were medications that significantly increased erectile dysfunction [12]. Also, polytherapy was significantly associated with erectile dysfunction $(\mathrm{OR}=3.7 ; \mathrm{p}=0.006)$. In France Hannon et al also showed that anti-hypertensive polytherapy was associated with erectile dysfunction [13].

Erectile dysfunction is severe in patients with hypertension. The presence of comorbidities explains this severity. This study showed that it was moderate to severe in $53.5 \%$ of cases.

Age was significantly associated with erectile dysfunction. It is mild before 60 years and moderate afterwards $(\mathrm{p}<0.001)$. 
This can be explained by a decrease in levels of androgens and increase in atherosclerosis with age. Studies also showed that erectile dysfunction can be due to age related apoptosis of the corporal smooth muscle cells due to oxidative stress. Also, $40 \%$ of men aged 40 have some form of erectile dysfunction [14].

Souleymane $\mathrm{P}$ et al in Togo found that the severity of erectile dysfunction increased with the stage of hypertension [3]. Similar results were obtained in this study, with mild erectile dysfunction in patients with controlled and stage 1 hypertension, moderate in those with stage 2 hypertension and severe in patients with stage 3 hypertension $(\mathrm{p}<0.001)$.

The severity of erectile dysfunction in our sample was also associated with the presence of other cardiovascular risk factors: diabetes $(p<0.001)$, tobacco smoking $(p=0.003)$. This can be due to the fact that they have a common pathophysiologic mechanism causing erectile dysfunction: atherosclerosis, reduction in the synthesis of nitric oxide, autonomic neuropathy.

Finally, chronic alcohol intake was associated with an increased severity of erectile dysfunction $(p=0.003)$. The effect of alcohol on erectile function is unclear, a metaanalysis found decreased odds of erectile dysfunction with moderate alcohol intake ( $<21$ drinks per week) [15]. On the other hand, it is generally accepted that there is a dose response relationship between heavy alcohol intake and erectile dysfunction $[15,16]$.

\section{Conclusion}

Erectile dysfunction has a high prevalence and severity in hypertensive Cameroonian patients. Age, duration of hypertension, stage of hypertension, diabetes, tobacco smoking, chronic alcohol intake, antihypertensive polytherapy and thiazide diuretics are factors associated with this high prevalence and severity. All these tend to have a common pathophysiology, causing atherosclerosis or vascular smooth muscle dysfunction. We recommend adequate control of blood pressure and other cardiovascular risk factors with a systematic screening of erectile dysfunction in hypertensive patients. Physicians should also be sensitised and encourage to discuss this issue with their patients to ensure adequate management of this condition, and improve their quality of life.

\section{References}

[1] Ibrahim A, Ali M, Kiernan TJ, Stack AG. Erectile Dysfunction and Ischaemic Heart Disease. Eur Cardiol Rev. 2018 Dec; 13 (2): 98-103.

[2] Feldman HA, Goldstein I, Hatzichristou DG et al. impotence and its medical and psychological correlates: results of Massachusetts Male Aging Study. J urol. 1994; 151 (1): 5461.
[3] Soulemane Pessinaba, Soodougoua B, Machihude P et al. La dysfonction érectile chez l'hypertendu togolais: étude transversale chez 100 patients dans le service de cardiologie du CHU campus de Lomé. Pan African Medical Journal. 2015; $21: 47-54$.

[4] Kearney PM, Whelton M, Reynolds K et al. Global burden of hypertension: analysis of worlwide data. Lancet. 2005; 365: 217-23.

[5] Kingue S, Ndong Ngoe C, Menanga AP et al. Prevalence and risk factors of hypertension in urban areas of Cameroon: a nationwide population-based cross-sectional study. The Journal of Clinical Hypertension. 2015 Oct; 17 (10): 819-24.

[6] Doumas $\mathrm{M}$ et al. Factors affecting the increased prevalence of erectile dysfunction in greek hypertensive compared with normotensive subjects. J Androl. 2006 May-Jun; 27 (3): 46977.

[7] Rosen RC, Cappeleri JC, Smith MD, Lipsky J, Pena BM. Development and evaluation of an abridged, 5 -item version of the international Index of Erectile Function (IIEF-5) as a diagnostic tool for erectile dysfunction. Int J Impot Res. 1999; 11 (6): 319-326.

[8] Buranakitjarsen P, Phoojaroenchanachai M, Sarawich S. Prevalence of erectile dysfunction among treated hypertensives males. J Med Assoc Thai. 2006 Nov; 89 (5): 28 36.

[9] Fafiolu AS, Adebayo AM, Akande TO et al. Erectile dysfunction among male hypertensive in a tertiary health facility in South-west Nigeria. Glob J Health Sci.2014 Aug 22; 7 (1): 154-60.

[10] Aranda P, Ruilope L, Calvo C et al. Erectile dysfunction in essential arterial hypertension and effects of sildenafil: results of spanish national study. Am J Hypertension. 2004; 17: 13945 .

[11] Javaroni V, Neves MF. Erectile dysfunction and hypertension: impact on cardiovascular risk and treatment. Int J Hypertens. 2012: 627-28

[12] Grimm RH, Grandits GA, Prineas RJ et al. Long term effects on sexual fucntion of five antihypertensive drugs and nutritional hygienic treatment in hypertensive men and women (TOHMS). Hypertension. 1997, 29: 8-14.

[13] Hanon O, Mounier V, Fauvel JP et al. Troubles de la sexualité chez les hypertendus traités. Arch Mal Cœur. 2002; 95: 67377.

[14] Ferrini MG, Gonzalez-Cadavid NF, Rajfer J. Aging related erectile dysfunction - potential mechanism to halt or delay its onset. Transl Androl Urol. 2017 Feb; 6 (1): 20-7.

[15] Wang X-M, Bai Y-J, Yang Y-B, Li J-H, Tang Y, Han P. Alcohol intake and risk of erectile dysfunction: a doseresponse meta-analysis of observational studies. Int $\mathrm{J}$ Impot Res. 2018 Nov; 30 (6): 342-51.

[16] Furukawa S, Sakai T, Niiya T, Miyaoka H, Miyake T, Yamamoto S, et al. Alcohol consumption and prevalence of erectile dysfunction in Japanese patients with type 2 diabetes mellitus: Baseline data from the Dogo Study. Alcohol Fayettev N. 2016; 55: 17-22. 